\title{
Teaching Philippine Literature and Illness: Finding Cure in Humanities
}

\author{
John Paolo Sarce \\ Lecturer, Ateneo de Manila University, Quezon City, Philippines. \\ Polytechnic University of the Philippines, Manila, Philippines. ORCID ID: 000o-0003-4428- \\ 778X.Email:john.sarce@obf.ateneo.edu
}

\begin{abstract}
Health and illness as themes are uncommonly being touched in literature classrooms. Other than the lack of interdisciplinary studies or specialists in this field in the Philippines, often teachers are also confronted with tons of materials that they are either overwhelmed to teach or find it difficult to deliver on their classes. This is the goal of this paper, help teachers gain confidence and basic knowledge of teaching literature that discusses health and illness especially at this time of history. Helping both teachers and students to understand and appreciate literature as a space for developing empathy while also honing their communicative and critical thinking skills. This paper will execute this goal by providing teachers in high school a guide in teaching literature that tackles health and illness using Philippine literature. I will translate theories and concepts from other studies into easy and clear language that teachers and students will find accessible to learn and use. And to organize this article, I will divide this into three parts the first is backgrounding and developing the framework in teaching literature about health and illness. Second, the application of the framework developed using two Philippine literature texts. And lastly, this paper will demonstrate how to teach Philippine literature that tackles health and illness using an online learning management system like Canvas or Google Classroom.
\end{abstract}

Keywords: Philippine Literature, Teaching Literature, Health Literature, Illness Literature, Medical Humanities

\section{I.}

Analyzing a text is like diagnosing a body, a work of art, a system or structure. Literature teachers train students to read texts, analyze, and understand each element of it from exposition, climax, to the denouement. And with the long tradition of literary studies, from formalist to queer studies, literature teachers are trained to examine, deliver, and select materials for their classes. Similarly, when a reader or teacher is analyzing a text, a doctor is reading signs that will lead to his diagnosis and recommendations. A careful reading of signs that aims to cure your ailing body. Therefore, through the habit of reading literature, teachers and students are also diagnosing a body whenever they read texts. This is the aim of this chapter to help teachers and students to read and analyze Philippine literature that discusses illness. This paper will help teachers of literature to refocus and redirect their reading practices on reading elements and themes of literature that deals with illness.

(C) AesthetixMS 2021. This Open Access article is published under a Creative Commons Attribution Non-Commercial 4.0 International License (http://creativecommons.org/licenses/by-nc/4.o/), which permits non-commercial re-use, distribution, and reproduction in any medium, provided the original work is properly cited. For citation use the DOI. For commercial re-use, please contact editor@rupkatha.com. 
First, this paper will briefly discuss background and theories in teaching literature and literature about illness in the Philippines. Second, the paper will demonstrate how the theories and concepts of illness and literature operate in a text. And lastly, this paper will demonstrate how teachers can teach literature about illness using a learning management system. To accomplish the goals mentioned above, I will use different concepts from literature, health, and illness studies and transpose these ideas to pedagogical realm and practices. Rice Soldier by Rina Garcia Chua and Potpot by Israfel Fagela are the texts that I will use in this paper as an example for teaching literature about illness and health.

II.

The teaching of literature seeks to hone the students' lifelong learning skills such as critical thinking and creativity. We develop different activities from literary materials to achieve such learning goals which are either mandated by our institutions or government agencies. Teaching through literature has been an integral part of developing students' capacity to become literate citizens. It polishes the skills of our students from reading, writing, listening, and speaking. In the Philippines with different approaches and designs for English classes whether by literary competence, reading competence, or language arts competence focused curriculum, the teaching of literature helps students to practice these macro skills and to refine their critical thinking and creativity. Teachers deliver literary texts and other multimodal texts in the classrooms to meet their learning objectives. These texts often open discussions about genre, form, and social issues. The Department of Education mandates teachers to teach different genres and forms of literature from fiction, poetry, and drama across the English language curriculum for elementary to senior high school. These classes are also expected to analyze different social issues embedded in literary text from class oppression, desires, to gender. However, though the Department of Education also encourages teachers to be creative with their classes, there is no mention of discussing health, illness, and disability about teaching literature for English classes. With this kind of premise, we have lost many chances to see how we can also train our students' critical thinking skills, creativity, and even the practice of empathy through literature that discusses illness as a condition in literary texts.

Teaching literature about illness helps students to understand several human experiences and conditions. This study conjures concepts on vulnerability, sympathy, empathy, melancholia, and other somatic pains and struggles. These concepts, however, and undeniably, are only possible through the narratives of fiction to drama and other multimodal texts. Narratives of illness, from the works of medical humanities, become an integral part of studying literature and its relationship with medicine especially after the pandemic crisis in the 1980s known as AIDS. Currently, several institutions across the globe offer program on Medical Humanities which seeks to train individualsstudents, scholars, or even medical professionals- in developing their skills and sensibilities in responding and understanding human suffering and pain through the practices and narratives of literary texts. The people behind these programs believe that the study of literature, illness, and medicine will help students and practitioners in their respective fields. Charon, R. et al (1995) even mention from their article that "Reading literary works and writing in narrative genres allow physicians and students to better understand patients' experience and to grow in selfunderstanding, and literary theory contributes to an ethical. satisfying, and effective practice of medicine." (p. 604). With these outcomes, we can devise a framework to help learners and teachers to study literature and medicine and achieve different learning objectives through concepts, elements, and themes of texts. 
III.

Illness Narratives. Narratives are the backbone of stories. Through plot, readers can follow the development of events and understand the issues or conflict of a text. As narrative unravels itself to the readers, we find ourselves intrigued by different issues that texts are revealing. Illness as a human condition is one of these themes which scholars often call illness narratives. These narratives of stories are formed or informed by illness as a human condition, the experience of the human body in sickness. Illness narrative, primarily, lets the readers become aware of how humans experience pain and suffering. It allows readers to see how illness or health conditions can drive the narrative of a story. Illness narrative is a development and series of events concerning illness as human experience reflecting in different texts. Moreover, as Ann Jurecic (2012) discusses from her book, illness narratives "[are about] the transformation of the self as it makes meaning of the body's fragility and life's finitude."(p. 102). From the narrative of these stories a learner may develop her sensibility and understanding about one's vulnerability, the experience of pain, and the limits of the human body.

A teacher may ask the following questions to understand illness as a narrative from a text: How did the text narrates the condition of the human body? What are the causes of the illness? And other factors that affect the human body as it experiences illness? These kinds of questions will help students to understand the relationship of illness as a narrative or part of the narrative. Whether the illness is only an ornament to the text, plays an integral role in the development of the narrative, or used as punishment the result of an action which reinforces problematic myths about illness, disease, or plagues.

Agents of Health. Characters and the persona of a text are also an important aspect of studying literature about health. One common notion about literature on health and illness is the traditional roles of doctors and patients. Usually, this role is seen as the active (doctor) and passive (patient) relationship which is a stereotyped and has problematic connection that must be rethought. This kind of representation usually reinforces the dominance of doctors over patients. It perpetuates a wrong conception of the supposedly harmonious and cooperative relationship between the agents. Characters exercise this kind of power through the concept of a gaze. A gaze is a way of looking and reading and, a doctor may diagnose an ailing body through this gaze. This kind of gaze from a dominant male medical figure may always be a way of looking to the body of a patient in either detached or voyeuristic manner. Meanwhile in this stereotyped relationship, a patient may gaze back as well to her doctor as someone skeptical, angry, confused, or hopeless. This conception of looking to each other from a certain privilege or positionality reinforces a problematic relationship between the characters of a story. Since the passive and active roles or tropes, other than in a troubled binary position, solidifies the signification of positive and negative meaning. Formation of representation in this manner preserves the same production of meaning based on binary opposition. An opposition or antagonism between characters tends to focus on the clashes and differences rather than relating to one another. To break this kind of relationship Johanna Shapiro (2002) encourages the practice of witnessing and recognition as a way of characters relating to one another. Understanding that the Self is also the Other. According to her "In literature, we find many instances of what might be termed witnessing or recognizing gazes. In these examples, we see the patient not as a passive, acted-upon object but rather as fully participatory in a relational process of mutuality and reciprocity." (p. 166). By changing the way characters see each other from a text that discusses illness, a better form of relationship arises from the agents of the texts. Instead of the antagonizing effect of differences through binary opposition, the shift to recognizing and 
witnessing rehearses the readers' minds to imagine a better relationship between the doctor and patient. A relationship founded on mutual understanding of pain and suffering.

Questions such as "Who are the characters?" "How the texts elicit the relationship between the doctor and patient? or with other characters?", "What are the factors affecting this relationship?", "What are the effects or changes in the relationship and treatment of the characters to one another?" are possible to be used in discussion to prompt the "doctor-patient" or other relationships and analyze it. The following questions will help students to critique certain power relations happening between characters and evaluate these exercises of power or influence if it is just or not. Further, this will help students to understand a better way of relating to one another through the practice of recognition and witnessing.

Vocabulary Pills. Language expresses the literary imagination. In literature, a way to analyze language is through style and diction. This is the examination of texts through language from lexical to discursive level. This examination includes the use of vocabulary, effects of words, construction of sentences, formation, and the relation of words and phrases. Indeed, it is inevitable to discuss language when we are dealing with literature. Literature is formed through language. It forms literature and polishes it across genres. As signs relate to each other, it constructs syntagms and systems of words and meanings that help readers to experience reading literature. Language, through words, metaphors, and expressions, creates meanings from a text. Illness literature contains these formations of meanings. One can be baffled by medical jargon or scientific terms that literature about illness has but these words should not hinder readers to understand a text rather it should enlighten them. For literature about illness or health that captures properly the human condition under these circumstances can explain to its reader the meaning of these medical terms through its discourse and narrative. Vocabularies and expressions about health and illness in these kinds of stories are used to narrate and describe the experiences of the human body. It challenges its readers and does not confuse them. As Vaidehi Ramanathan (2010) explains from his book "Connections between language/s and ailments are multidirectional and intertwined, and 'disability experiences' are not just constructs that emerge through language, but ones that construct as well, with each of us carrying traces of disability experiences in our minds, bodies, behaviors and languaging. In the case of those living with chronic ailments, this point assumes poignant overtones."(p. 64). Language is related to how we experience our bodies under certain circumstances. Language affects our conception and understanding of our health and illness. Our body as a system communicates through its cells, hormones, and organs to express certain health conditions. We translate these conditions into the language to explain it and make others understand it. Our experiences of health and illness is translatable into different words, expressions, and stories or if not, it is language that explains and constructs the different experiences of illness and health. Medical terms, vocabulary, expression, and discourse when present in a text that discusses illness and health, even if we have not personally experienced it, allow us as readers to understand it.

In discussing the language of literature about illness and health, teachers may ask questions like "What are the unfamiliar words you found from the texts?", "How do the texts explain these terms?", "Are there any context clues to help you understand these words and expressions?", "What are unique words or expression about health or illness from the text?", "What is the meaning of it outside the texts?" these will help readers to direct their attention to language as part of learning literature. Students will be able to sharpen their vocabulary skills and practice health literacy by becoming familiar with these words or expressions and their function in a text. 
Caring Readers. The last aspect of this framework is reading as a process which does not only decodes signs from a text but also plays an important part in reading stories about illness and health. This aspect of teaching literature about illness and health is an interactive one. Since this will talk about the role of the learner in terms of reading texts about suffering and pain. Similarly, with J. Shapiro's study on ethical gaze, reading literature about illness and health is a form of witnessing and recognizing. Readers do not just read the text in these cases, but they are also witnessing the suffering of a human through illness. They also witness the health condition of a person or how health works in a system. And to witness such acts or slices of life, it requires us to recognize these pains and sufferings of others. It requires us to practice empathy and relate our experiences from the text to one another. Other than training students as readers, the literature about illness and health also sharpens students' knowledge of health literacy, and critical thinking. However, the stories about health and illness are not just like any other story. These stories depict human suffering and wide accounts of the human experiences of pain from cancer survivors to dying patients. We as readers cannot and should not reduce these accounts as a mere troping of reality. Rather, we should approach these kinds of texts as caring readers. A reader who cares about the human condition. A reader who understands how to practice caring to others through the literature about health and illness. A caring reader who learns to witness and recognize the pain and suffering the others. A reader, that despite being aware that these texts are fictional, can still understand that these texts share accounts of reality. A reader who knows that to read literature about health and illness is to read and experience life. Same with Josie Billington's (2016) argument "Health here is not just healthy-mindedness; any more than literature is just about problems or sorrows. Health is not just about cures for illnesses. It is about letting in and giving out more life and more thought, and finding space and a place in which to think everything and anything."(p. 136).The issue of health and illness, whether a theme or an aspect of a text, is not confined within the literary world. Further, training students to read texts align with these concerns do not train them to become passive consumers of texts. Rather, by engaging our students with literature about illness and health, we aim them to be caring and critical readers.

To practice these aims, a teacher may ask the following questions "What are your thoughts or feelings about the issues presented by the text?", "Which among the characters can you relate the best and why?", "If you are the persona or any character from the texts how will you respond from these circumstances?", "As a student what can you do for the community being narrated from the texts?", "What are the issues or situations we are experiencing right now similar to the text and how can we help or respond unto it?” These questions connect the reader from the text. These questions also challenge the students to deepen their understanding of the text. Furthermore, these also train students to think about how a text can be connected to reality and other social realities that asks them to actively participate in contributing and solving problems. With this, we hope to develop not just health literate students nor critical thinkers but also caring readers through illness and health literature.

IV.

The Rice Soldier of Rina Garcia Chua follows the lives of Elizabeth and her unnamed father. The story is told through Elizabeth's father a kind of narration that has several flashbacks of Elizabeth's childhood. The problem started when Elizabeth's father had several dreams and hallucinations. This pushed Elizabeth to her limits and argue which later triggered her father's stroke. Afterward, it was revealed that the stroke was caused by his hyperactivity due to his dreams and hallucinations. 
Despite unresolved issues, Elizabeth chooses to stay with her father and make him realize that his health matters for both of them.

Below is a table of applying the concepts discussed above for the text Rice Soldier. To provide a clear and strong reading, teachers of literature should always ask their students to provide textual evidence. Answers may still vary but highly defends on textual evidence.

\begin{tabular}{|c|c|c|}
\hline Aspect/Theme & Analysis & Textual Evidence \\
\hline Illness as Narrative & $\begin{array}{l}\text { The text narrates the story through } \\
\text { flashbacks and its relation to the present } \\
\text { time. The flashback is a continuous } \\
\text { element from the text, and it recalls a lot } \\
\text { of memories of Elizabeth as a child. The } \\
\text { text unravels the mental health problem } \\
\text { of the father after he had a dream and } \\
\text { accuses Elizabeth of betraying him. } \\
\text { Elizabeth, out of frustration, screams at } \\
\text { her father and told him that he is sick. } \\
\text { Afterward, her father had a stroke but } \\
\text { through her love and care, they were } \\
\text { able to mend their relationship. } \\
\text { The illness from this narrative is implied } \\
\text { with the father's inconsistent narration } \\
\text { of the story. Which is later revealed that } \\
\text { the cause of his stroke is his } \\
\text { hyperactivity due to his dreams, } \\
\text { distress, and hallucinations. } \\
\text { The narrative of the text itself is a } \\
\text { manifestation of the father's mental } \\
\text { health condition. It shows how a } \\
\text { distressful mind suffers from different } \\
\text { images, dreams, and disappointments in } \\
\text { life. The illness narrative from the text is } \\
\text { composed of memories, flashbacks, and } \\
\text { distressful experiences from the present } \\
\text { time. And the story narrates how mental } \\
\text { condition and hyperactivity may result } \\
\text { in other health conditions like stroke. } \\
\text { The narrative sutures different illnesses } \\
\text { and how each of these illnesses can be } \\
\text { related to one another. Like how } \\
\text { narrative develops itself, a story of a } \\
\text { series of events, the illness from this } \\
\text { story is also about how the human body } \\
\text { experiences a series of somatic } \\
\text { conditions. }\end{array}$ & $\begin{array}{l}\text { "Papa, why do you think grandma } \\
\text { and Mama left you, huh? Papa, } \\
\text { you're sick! You need to go and } \\
\text { see a doctor as soon as possible } \\
\text { because I don't know how much } \\
\text { more of this I can take!" (pg. 139- } \\
\text { 140) } \\
\text { "Then, I feel something hit the } \\
\text { back of my head-so sudden, so } \\
\text { fast, so painful-that I double } \\
\text { over and collapse to the floor." } \\
\text { (pg. 140) } \\
\text { "Papa, he referred me to a } \\
\text { psychiatrist and they think that } \\
\text { these pills may help you. Umm, } \\
\text { they say that your stroke may } \\
\text { have been a direct result of your } \\
\text { hyperactivity due to your ...” A } \\
\text { psychiatrist? I flare up at her } \\
\text { insinuation. "I'm not crazy, } \\
\text { Elizabeth!" I try to shout out, but } \\
\text { it comes out more garbled than } \\
\text { alarmed" (pg. 141) }\end{array}$ \\
\hline
\end{tabular}




\begin{tabular}{|c|c|c|}
\hline Agents of Health & $\begin{array}{l}\text { The doctor \& patient relationship is not } \\
\text { clear from the text. Since the text seems } \\
\text { to be avoiding the figure of doctor based } \\
\text { on its narration. But later discovered as } \\
\text { the father's (as patient) way of refusing } \\
\text { to acknowledge his health problems. } \\
\text { Meanwhile, Elizabeth, the mother, and } \\
\text { the grandmother are also affected by the } \\
\text { health condition of the father. The } \\
\text { mother and grandmother distant } \\
\text { themselves from him because of his } \\
\text { condition while Elizabeth constantly } \\
\text { stayed in his life. Elizabeth endures } \\
\text { everything since she was a little girl. } \\
\text { Elizabeth also learns how to read her } \\
\text { father when he is having episodes of } \\
\text { mental distress. } \\
\text { Further, Elizabeth somehow becomes } \\
\text { an extension of the doctor/physician } \\
\text { identity after she explains to her father } \\
\text { his situation. Narrating what happened } \\
\text { after they argued and convincing him to } \\
\text { drink his medicine. Even if her father } \\
\text { consistently refuses her help and } \\
\text { maligned her, she stayed, and she } \\
\text { continues to understand him. She } \\
\text { endures all the pain that her father } \\
\text { caused to her the same way her father } \\
\text { suffers from pain. This eventually leads } \\
\text { to the father allowing himself to } \\
\text { cooperate with his daughter and agree } \\
\text { to heal himself while also mending their } \\
\text { relationship. }\end{array}$ & $\begin{array}{l}\text { ““'m not crazy, Elizabeth!" I try } \\
\text { to scream once again." (pg. 141) } \\
\text { "Elizabeth studies my face quietly } \\
\text { before she says, "I'm not lying to } \\
\text { you, Papa. You need to get some } \\
\text { sleep." (pg. 138) } \\
\text { "She hits the table with her fist } \\
\text { and kicks the foot of my bed. She } \\
\text { turns her back to me so that I } \\
\text { don't get the pleasure of seeing } \\
\text { her frustration. We stay for a } \\
\text { while in that terse standoff." (pg. } \\
\text { 141) } \\
\text { "Elizabeth gently places her } \\
\text { spoon and fork on the plate, } \\
\text { making sure they are aligned, and } \\
\text { stands up. She moves towards me } \\
\text { and sits carefully at the edge of } \\
\text { my bed's cushion. She takes my } \\
\text { hand. I shouldn't, but I let her." } \\
\text { (pg. 142-143) }\end{array}$ \\
\hline
\end{tabular}

Table 1.o Analysis Table for Rice Soldier

The second story is Potpot by Israfel Fagela. A story that narrates the life of Potpot before and after she died through an omniscient narrator. The story starts on Potpot's wake while her cousin Charito is assisting on it. Indang Undang a relative of the family arrives from the wake and starts to ask questions about Potpot. She noticed that the casket is weird, and Charito replied that it is because of Potpot's complicated disease. Both of them recalled and started to wonder the reason behind Potpot's weird attitude toward her illness. First, Potpot stops eating and taking her medicine after finding out her fifth stage cancer. This shocks the family and makes them worried. Then this stunt is followed by unexplainable actions like releasing all their family pets to the street and collecting all the holy figures in the neighborhood to display in front of her house. Most people are confused but some were irritated too like her cousin Meldy. She thinks that the reason for the smell coming out of Potpot's casket is a punishment by God for being blasphemous. Towards the 
end, Charito had reflected on life and felt bad about her cousin. This even went to some extent of Charito defending her cousin to her husband who called her "Fatty". The story ended with Charito regretting not knowing her cousin well while she is still alive and wishing that in the afterlife she is at peace.

\begin{tabular}{|c|c|c|}
\hline Aspect/Theme & Analysis & Textual Evidence \\
\hline Vocabulary Pills & $\begin{array}{l}\text { The story uses a lot of terms to define } \\
\text { the illness of Potpot. However, these } \\
\text { terms arise more likely because they do } \\
\text { not know well Popot. "Renal Disease" is } \\
\text { the first one mentioned by Charito. } \\
\text { Charito also used the term "prognosis". } \\
\text { But the term prognosis here is used in } \\
\text { animation. Since according to Charito, it } \\
\text { is as if the doctor's prognosis turns off } \\
\text { the switch of Potpot on eating and will } \\
\text { to live. It is actually not the doctor who } \\
\text { caused her suffering but the diagnosis of } \\
\text { the doctor. } \\
\text { "Force feeding" is also employed in the } \\
\text { text to describe the gravity of Potpot's } \\
\text { withdrawal from life. Family members } \\
\text { try to feed her, but she refuses to do so } \\
\text { and even removing her own dextrose } \\
\text { which is her support other than food. } \\
\text { "shutting her body down system by } \\
\text { system" phrase was also used to describe } \\
\text { how Potpot slowly died by not taking } \\
\text { any medicine nor eating properly. } \\
\text { coming out from Potpot's casket. } \\
\text { However, the word "stink" here is not } \\
\text { just an odor it was used as an index } \\
\text { relating it to another disease of Potpot } \\
\text { which is diabetes. Further, Meldy } \\
\text { believes that her body is releasing a bad } \\
\text { odor because God is punishing her for } \\
\text { getting Meldy's holy figurine. }\end{array}$ & $\begin{array}{l}\text { "But as soon as she heard the } \\
\text { news from the doctor at the } \\
\text { Provincial Hospital that she had } \\
\text { stage five renal disease, she just } \\
\text { stopped eating, as though the } \\
\text { prognosis itself crawled out of the } \\
\text { doctor's mouth and flicked the off } \\
\text { switch on the feeder belt of fatty } \\
\text { and salty excess that fueled } \\
\text { Potpot's desire to live." (pg 3-4) } \\
\text { "Force feeding Potpot was as } \\
\text { effectual as feeding coins into a } \\
\text { vomit machine. She would not } \\
\text { hold anything in... Near the end } \\
\text { her arms had to be restrained to } \\
\text { stop her from tearing out the } \\
\text { tubes from her dextrose bottle." } \\
\text { (pg. } 4 \text { ) } \\
\text { "Potpot was fine with being } \\
\text { ignored... It was as though Potpot } \\
\text { were shutting her body down } \\
\text { system by system. In a week, she } \\
\text { was gone." (pg. } 6 \text { ) }\end{array}$ \\
\hline Caring Reader & $\begin{array}{l}\text { I felt that of all the characters I can be } \\
\text { Charito. Someone who will care and } \\
\text { defend a relative especially when they } \\
\text { are already dead. However, even if } \\
\text { Charito had these realizations about the }\end{array}$ & $\begin{array}{l}\text { "“Poor cousin," Charito thought. } \\
\text { "Nobody knew you." She tried to } \\
\text { but could not sleep so she tried } \\
\text { praying instead. Although she } \\
\text { had no saints in the house and }\end{array}$ \\
\hline
\end{tabular}




\begin{tabular}{|l|l|l|}
\hline & $\begin{array}{l}\text { importance of life and how terrible } \\
\text { people have treated Potpot, she could }\end{array}$ & $\begin{array}{l}\text { she was not raised with religion, } \\
\text { have done things and help her out even } \\
\text { shagined her questions } \\
\text { before she died. The way Charito and } \\
\text { wndang talk about Potpot is both from } \\
\text { afterlife" (pg. 9) Potpot in an }\end{array}$ \\
a distance as if Potpot is a stranger to \\
them. Though I commend Charito's \\
dedication to help and defend Potpot, \\
maybe she could have done more when \\
Potpot is still alive. Know more about \\
her cousin and understand her pain \\
while she is still living not after she died. \\
Maybe changes could have happened \\
through that. It might not save Potpot \\
from death but at least it will make her \\
feel alive.
\end{tabular}

Table 2.o Analysis Table for Potpot

The answers from the tables above are just example of analysis. Teachers may still choose and create different questions that are related to the concepts, themes, or aspect of literature about illness to elicit important ideas from the text and achieve different learning goals. Teachers can explore the aspects of Philippine literature about illness and health and interchange each aspects or elements in discussing texts.

V.

Currently, due to the pandemic, teachers and students are forced to migrate online to continue schooling. Teachers are burdened to evaluate different learning management platforms that best suit their classes, and, in my case, I use google classroom for most of my classes. To discuss online teaching about Philippine Literature on health and illness, I will use the said platform to explain and propose activities in teaching literature.

Philippine Department of Education curriculum guide for English 10 requires students to achieve some standards on studying literature in English for the third quarter of the school year. These standards are to demonstrate communicative competence through understanding literature and other texts, understand different cultures and aspects of literature, and learn how to resolves conflicts reflecting from different texts. Clearly, the DepEd encourages teachers of English to use different literary texts to teach different cultures and learn English language. It aims to hone students critical thinking skills by understanding conflicts, cultures, and forms of texts. Then challenges students to use these skills in different activities and class performances.

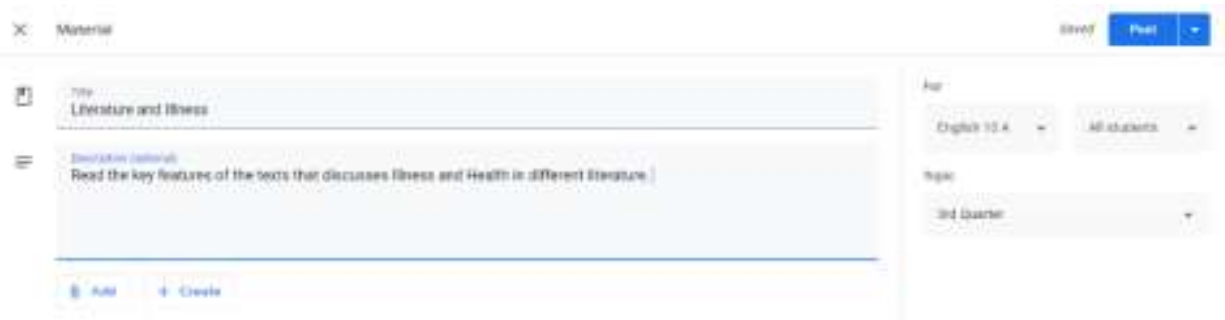

Figure 1.o Screen capture Assigning Material 
Teachers using google classroom may do the following tips. First teachers must assign reading materials to students that briefly review the past lessons on structuralist, formalist, moralist, marxist, feminist, and historical literary texts. This will help students to recall some key points and elements of a text which is also present in literature about an illness like plot, conflict, theme, and characters. After supplying quick review notes, teachers summarize the features or elements of literature about illness and health. These are the features discussed above. Teachers may paraphrase or even read other sources to elaborate on each feature. Using the same button on uploading review and introduction materials, teachers may start to upload the stories analyzed above and either of the two will work for the class. Both texts are also possible to be used in the class depending on the strategy of the teacher and the planned assessment. Upon giving the readings, teachers must encourage students to close read the stories, highlight parts of the stories, and write notes about it. These annotations will help them to remember important or memorable details about the texts.

The eighth week of the DepEd (2016) curriculum guide advises that a learner must "Identifying textual details that affirm or refute a claim", "Draw similarities and differences of the featured selections in relation to the theme", and "Compose an independent critique of a chosen selection". These competencies were set as the minimum standard of the Department of Education and teachers can always add more goals and activities to this. After assigning the text to the class, teachers can begin the class by posting a question about the text where students may answer and participate in the discussion. Questions like "Did you like the text or not?" or "Which part of the text you like the most?" These questions encourage students to participate in the class by sharing their own experience upon reading the text.

Teachers may proceed to discuss the text from elements to themes. Asking textual questions for discussion helps teachers to see how well students pay attention to the details of the story and validates their answer through textual facts. Questions like "Who are the main characters?", "What is the conflict/climax of the text?", or "How the conflict was resolved in the story?". Teachers should also encourage students to share their opinion about the themes of the texts. This will allow each student to feel connected from the story and be part of the class discussion. For assessment, teachers can use google forms in creating questions for the students which the system will automatically collect. For this activity, it is highly encouraged that teachers train their students on supporting their analysis by providing textual evidence. This will train students to refute or affirm a claim.

Richard Beach, et al., (2006) recommended that evaluating the students answer on interpreting thematic meaning teachers may use these three descriptions. "Criteria: if students can interpret larger themes by inferring the underlying values assumptions inherent in characters' actions related to the norms operating systems in the text world. Exemplary (5) if students interpret a theme(s) by clearly defining the value assumptions inherent in detailed descriptions of characters' actions related to the norms operating in the text world. Proficient (3) Interprets a theme(s) by defining the value assumptions inherent in characters' actions related to the norms operating in the text world. Needs Work(2) Infers character's actions, but does not define a value assumption inherent those characters' actions."(p.233) Teachers who are using numbers in grading students can still give a different numerical value for each description so it will be easy for them to compute scores. Teachers' may also combine this rubric with other that will cater literacy or language to deepen and widen their learning objectives. This activity will train students to affirm or refute their analysis based on a given text. Further, this will help students to compose a simple analysis of a critique using a text that they have read. Lastly, as an assignment, teachers my use Potpot by I Fagela and 
ask students to write a short essay comparing and contrasting the elements or themes of the two stories. Teachers may also add questions highlighting specific Filipino cultures that students can read from the text. We can ask them to explain and connect these cultures into their realities. If they have seen or witness same events from Filipino movies or personal experiences. These activities while still following and being aligned with Dep Ed's mandate will help teachers to discuss Philippine literature on illness and health.

\section{VI.}

Teachers are confronted with tons of materials to be used in their everyday classes. And with the pandemic causing changes in learning systems, we are struggling to find the best way to teach and help our students. The discussion above on using google classroom for teaching students about literature on illness is just one of the ways we can do it. Teachers may also start the class by providing materials like commercials, pictures, paintings, or even music about health and illness that can be used as a springboard. However, one thing that this paper would like to believe is that the importance of exploring the interdisciplinarity of our subjects and teaching health and illness through literature. For I believe that beyond following the government standards, competencies, or sharpening health literacy, teaching literature about illness and health will help our students to connect the text world into their realities through the practice of empathy and understanding the pain and suffering of a human body not as other but as self as well. Further, students will learn to evaluate systems that affect our bodies, and that illness is both social and biological condition affected by different systems.

\section{References}

Billington, J. (2016). Is Literature Healthy?: The Literary Agenda. Oxford: Oxford University Press.

Beach, R., Appleman, D., Hynds, S., \& Wilhelm, J. D. (2006). Teaching Literature to Adolescents. New Jersey: LEA.

Charon, R., Banks, J., Hawkins, A., Hunter, ,., Jones, A., Montello, M., \& Poirer, S. (1995). Literature and Medicine: Contributions to Clinical Practice. Annals of Internal Medicine.

Chua, R. (2017). Rice Soldier. Thomas, 2(9), 130-140. Retrieved September 20, 2020, from https://tomas.ust.edu.ph/volumes/volume-2-issue-9-the-anniversary-issue/.

Fagela, I. (2019). Potpot. Likhaan, 13, 3-9. Retrieved September 17, 2020, from https://journals.upd.edu.ph/index.php/lik/article/view/6966/6048

Jurecic, A. (2012). Illness as Narrative. Pittsburgh: University of Pittsburgh Press

Ramanathan, V. (2010). Bodies and Language: Health, Ailments, Disabilities. Bristol: Multilingual Matters.

Shapiro, J. (2002). (Re)examining the Clinical Gaze through the Prism of Literature. Families, Systems, $\mathcal{E}$ Health, 20(2), 161-170. doi:10.1037/hoo89492

John Paolo Sarce is a lecturer at Ateneo de Manila University and Polytechnic University of the Philippines. He teaches courses on cultural studies, literature, and pedagogy. His projects are focused on postcolonialism, queer theory, medical humanities, digital humanities, and pedagogy. In his free time, he likes to watch RPDR and anime and then cram for his writing projects. Zodiac sign is his guide to life while reading books is his way of breathing life. 